\title{
Analysis of loss of heterozygosity and $X$ chromosome inactivation in spleens with myeloproliferative disorders and acute myeloid leukemia
}

\author{
Dennis P O’Malley, Attilio Orazi, Mingsheng Wang and Liang Cheng \\ Department of Pathology and Laboratory Medicine, Indiana University School of Medicine, Indianapolis, \\ IN, USA
}

\begin{abstract}
Neoplastic myeloid proliferations are seen in the spleens of some patients with acute and chronic myeloproliferative disorders. Both acute myeloid leukemia (AML) and chronic myeloproliferative disorders have a variety of underlying cytogenetic defects that can be evaluated by loss of heterozygosity (LOH) studies. LOH studies have advantages over conventional cytogenetics by allowing the use of archival tissues. We evaluated the spleens in AML and chronic myeloproliferative disorders with neoplastic myeloid proliferations for the presence of LOH at several chromosome loci, and X-chromosome inactivation. A total of 17 spleens were evaluated (chronic myelogenous leukemia =6; chronic idiopathic myelofibrosis =6; essential thrombocythemia $=1$; $A M L$ arising from previous chronic myeloproliferative disorders $=4$ ). We examined LOH loci $7 q$ (D7S2554), 8q (D8S263), 9p (D9S157, D9S161), 13q (D13S319), common sites of genetic abnormality in chronic myeloproliferative disorders, and TP53. In six cases, spleen LOH findings were compared to those of concurrent or preceding bone marrow biopsies. Five spleens of female patients were evaluated for the presence of clonality using X-chromosome inactivation. Of the 16 cases analyzed, $14(88 \%)$ had at least one abnormal LOH locus, with 6/16 with two abnormal loci. The abnormalities were distributed as follows: D9S161-7/15 (47\%), TP53-6/16 (38\%), D7S2554-5/16 (31\%), D9S157-5/15 (33\%), D8S263-3/14 (21\%), and D13S319-2/14 (14\%). Of the six bone marrows, 4/6 showed concordance in bone marrow and spleen specimens, with additional LOH abnormalities being identified in the spleen specimens of all four cases. X-chromosome inactivation studies were showed nonrandom (clonal) patterns in two cases. Our results show that allelic losses were common in the neoplastic extramedullary hematopoiesis found in spleens of chronic myeloproliferative disorders and AML. Comparison of spleen and bone marrow specimens by LOH demonstrated additional abnormalities in the spleen compared to the marrow.
\end{abstract}

Modern Pathology (2005) 18, 1562-1568. doi:10.1038/modpathol.3800481; published online 19 August 2005

Keywords: chronic myeloproliferative disorders; loss of heterozygosity; spleen; acute myeloid leukemia; $\mathrm{X}$ chromosome inactivation; extramedullary hematopoiesis

Neoplastic hematopoietic proliferations can be seen in the spleens of patients with acute and chronic myeloid neoplasms. It occurs particularly frequently in patients with chronic myeloproliferative disorders, especially in chronic idiopathic myelofibrosis and chronic myelogenous leukemia (CML). ${ }^{1-3}$ In addition, spleen is a common site of

Correspondence: Dr DP O’Malley, MD, Department of Pathology and Laboratory Medicine, Indiana University School of Medicine, 702 Barnhill Drive, Riley 0969, Indianapolis, IN 46202, USA.

E-mail: dpomalle@iupui.edu

Received 29 April 2005; revised 30 June 2005; accepted 1 July 2005; published online 19 August 2005 blastic transformation in chronic myeloproliferative disorder. ${ }^{4}$

Both acute myeloid leukemias (AML) and chronic myeloproliferative disorders have a variety of underlying molecular and cytogenetic defects. Loss of heterozygosity (LOH) has been used previously to detect genetic imbalances in these disorders, with several genetic loci being commonly involved. LOH evaluation provides an advantage over conventional cytogenetics because of the ability to evaluate archival, paraffin-fixed tissue samples. We chose to evaluate six chromosomal loci that have been shown to be frequently abnormal in chronic myeloproliferative disorder. ${ }^{5-8}$ We evaluated spleens with chronic myeloproliferative disorders and AML that 
arose from previous chronic myeloproliferative disorder and with extensive neoplastic myeloid proliferations for the presence $\mathrm{LOH}$ at the selected loci. Further, we evaluated clonality in female patient samples using X-chromosome inactivation analysis. Finally, we evaluated LOH loci in six bone marrows with chronic myeloproliferative disorder that preceded or were concurrent with splenectomy specimens, and compared those results to the findings in the corresponding splenectomy.

\section{Methods}

\section{Tissue Samples and Microdissection}

Archival surgical materials from 17 patients with splenectomy were retrieved from the surgical pathology files of the Department of Pathology and Laboratory Medicine of the Indiana University School of Medicine (Indianapolis, IN). Cases were selected for the presence of extensive neoplastic myeloid proliferations $(\mathrm{CML}=6$; chronic idiopathic myelofibrosis $=6$; essential thrombocythemia $=1$; AML arising from previous chronic myeloproliferative disorder $=4$ ). In six cases, bone marrow biopsies that preceded or were concurrent with the splenectomy specimens were retrieved and reviewed. Three cases with extensive benign EMH were included for comparison (autoimmune hemolytic anemia $=1$, thrombotic thrombocytopenic purpura $=1$, fibrocongestive splenomegaly $=1$ ).

Histologic sections were prepared from formalinfixed, paraffin-embedded tissue and were stained with hematoxylin and eosin for microscopic evaluation. Laser-assisted microdissection was performed (Figure 1), separating neoplastic myeloid proliferations from normal control tissues (residual lymphoid tissues) on unstained sections using a PixCell II Laser Capture Microdissection system (Arcturus Engineering, Mountain View, CA, USA), as previously described. ${ }^{9-14}$

\section{Detection of $\mathrm{LOH}$}

The dissected cells were deparaffinized with $x y-$ lene and ethyl alcohol. Polymerase chain reaction (PCR) was used to amplify genomic DNA at six specific loci on five different chromosomes: 7q31.1 (D7S2554), 8q24 (D8S263), 9p21 (D9S157, D9S161), 13q14 (D13S319), and 17p13 (TP53). Previous studies have demonstrated that $\mathrm{LOH}$ at these loci occurs in chronic myeloproliferative disorders. ${ }^{5-8}$ A summary of these loci, and their relation to important genes is presented in Table 1 . PCR amplification and gel electrophoresis were performed as previously described..$^{9-14}$ The criterion for allelic loss was complete or nearly complete absence of one allele in tumor DNA. ${ }^{9-14}$ PCRs for each polymorphic microsatellite marker were repeated at least twice from the same DNA preparations and the same results were obtained.
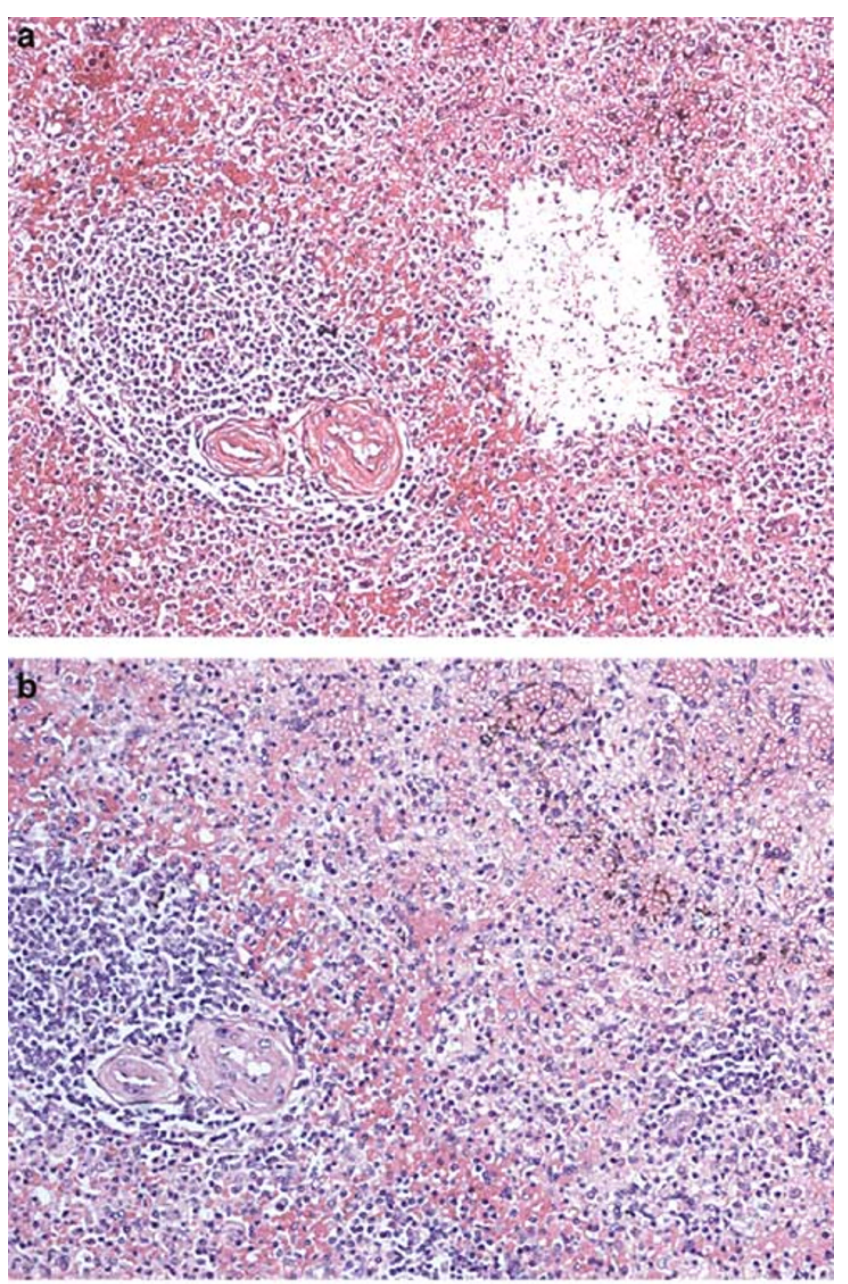

c

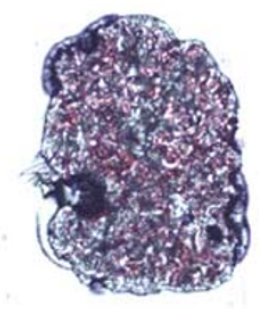

Figure 1 Laser capture microdissection. Splenic tissue with laser capture microdissection of red pulp (a), and same tissue before microdissection (b). (c) Tissue dissected, which was used for $\mathrm{LOH}$ or X-chromosome inactivation studies.

\section{Detection of X-Chromosome Inactivation}

$\mathrm{X}$-chromosome inactivation analysis was performed on spleen samples from five female patients, using techniques previously described. ${ }^{11}$ DNA samples were prepared as for $\mathrm{LOH}$ studies. The dissected 
Table 1 LOH loci evaluated

\begin{tabular}{lll}
\hline Chromosome & Locus & Gene/location \\
\hline 7q31.1 & D7S2554 & Putative tumor suppressor gene \\
8q24 & D8S263 & Telomeric to MYC \\
9p21 & D9S157 & Telomeric to p16 \\
9p21 & D9S161 & Centromeric to p16 \\
13q14 & D13S319 & Telomeric to $R B$ \\
17p13 & p53 & TP53 \\
\hline
\end{tabular}

cells were placed in $50 \mu \mathrm{l}$ of buffer (ie $10 \mathrm{mM}$ Tris$\mathrm{HCl}, 1 \mathrm{mM}$ EDTA, $1 \%$ Tween 20 , and $3 \mathrm{mg} / \mathrm{ml}$ of proteinase $\mathrm{K}(\mathrm{pH}$ 8.3) and incubated overnight at $37^{\circ} \mathrm{C}$. The solution was boiled for $10 \mathrm{~min}$ to inactivate the proteinase $\mathrm{K}$ and used directly for subsequent clonal analysis without further purification. Aliquots $(8 \mu \mathrm{l})$ of the DNA extract were digested overnight at $37^{\circ} \mathrm{C}$ with $1 \mathrm{U}$ of HhaI restriction endonuclease (New England Biolabs Inc., Beverly, MA, USA) in a total volume of $10 \mu \mathrm{l}$. Equivalent aliquots of the DNA extracts were also incubated in the digestion buffer without HhaI endonuclease as control reactions for each sample. After the incubation, $3 \mu \mathrm{l}$ of digested or nondigested DNA was amplified in a $25-\mu$ l PCR volume containing $0.1 \mu \mathrm{l}{ }^{32}[\mathrm{P}] \alpha$-labeled deoxyadenosine triphosphate (dATP) $(3000 \mathrm{Ci} / \mathrm{mmol}), \quad 0.8 \mu \mathrm{M}$ AR-sense primer (5'TCC AGA ATC TGT TCC AGA GCG TGC3'), $0.8 \mu \mathrm{M}$ AR-antisense primer (5'GCT GTG AAG GTT GCT GTT CCT CAT3'), 4\% dimethyl sulfoxide, $2.5 \mathrm{mM} \mathrm{MgCl}{ }_{2}, 150 \mu \mathrm{M}$ deoxycytidine triphosphate, $150 \mu \mathrm{M}$ deoxythymidine triphoshpate, $150 \mu \mathrm{M}$ deoxyguanosine triphosphate, $120 \mu \mathrm{M}$ deoxyadenosine triphosphate, and $0.13 \mathrm{U}$ Taq DNA polymerase (Perkin-Elmer Corp., Norwalk, CT, USA). Each PCR amplification had an initial denaturation step of $95^{\circ} \mathrm{C}$ for $8 \mathrm{~min}$, followed by 38 cycles at $95^{\circ} \mathrm{C}$ for $40 \mathrm{~s}$, at $63^{\circ} \mathrm{C}$ for $40 \mathrm{~s}$, and at $72^{\circ} \mathrm{C}$ for $60 \mathrm{~s}$ and then followed by a single final extension step at $72^{\circ} \mathrm{C}$ for $10 \mathrm{~min}$. The PCR products were then diluted with $4 \mu \mathrm{l}$ of loading buffer containing $95 \%$ formamide, $20 \mathrm{mM}$ EDTA, $0.05 \%$ bromphenol blue, and $0.05 \%$ xylene cyanole FF (Sigma Chemical Co., St Louis, MO, USA). The samples were heated to $95^{\circ} \mathrm{C}$ for $5 \mathrm{~min}$ and then placed on ice. In total, $3 \mu \mathrm{l}$ of the reaction mixture was loaded onto $6.5 \%$ polyacrylamidedenaturing gels without formamide, and the PCR products were separated by electrophoresis at $80 \mathrm{~W}$ for $2 \mathrm{~h}$. The bands were visualized after autoradiography with Kodak X-OMAT film (Eastman Kodak Company, Rochester, NY, USA) for 8-16 h (Figure 2).

\section{Analysis of X-Chromosome Inactivation}

The cases were considered to be informative if two androgen receptor allelic bands were detected after
PCR amplification in normal control samples that had not been treated with HhaI. Only informative cases (ie, those without a skewed pattern of Xchromosome inactivation after being treated with HhaI in normal control samples) were included in the analysis. In tumor samples, nonrandom Xchromosome inactivation was defined as a complete or a nearly complete absence of an androgen receptor allele after HhaI digestion, which indicated a predominance of one allele.

\section{Results}

\section{LOH Spleen}

Of the 17 spleens with neoplastic myeloid proliferations studied, 16/17 had informative results in both normal and tumoral tissue for at least four of the six probes tested. These results are summarized in Table 2 and Figures 3-5. Of the 16 cases, $14(88 \%)$ had at least one abnormal LOH locus, with 6/16 with two abnormal loci and 4/16 with three abnormal loci. The abnormalities were distributed as follows: D9S161-7/15, TP53-6/16, D7S2554-5/16, D9S1575/15, D8S263-3/14, and D13S319-2/14. No LOH was seen in the paired negative control tissues. In the three spleens with benign EMH, no $\mathrm{LOH}$ was seen at any loci.

\section{X-Chromosome Inactivation Studies}

Of the five cases evaluated, one was noninformative. Of the remaining four cases, two had evidence of clonality as measured by nonrandom X-chromosome inactivation. Although clonal origin was not proven for two of the cases, these cases did show evidence of $\mathrm{LOH}$ abnormalities, suggesting clonality.

\section{LOH: Comparison of Spleen and Bone Marrow}

In six cases, bone marrow biopsies that preceded or were concurrent with the splenic biopsies were evaluated for the same panel of LOH loci abnormalities. In 6/6 cases studied, there were identified differences in the LOH patterns between the spleen and bone marrow samples. These results are summarized in Table 3 . In general, $4 / 6$ cases had one $(n=3)$ or two $(n=1)$ additional abnormalities in the spleen compared to the bone marrow. In one of the other cases (case 1-CML), the spleen showed no LOH abnormalities, while the marrow showed two abnormal loci. In the final case (case 6-chronic idiopathic myelofibrosis), there were two entirely

Figure 2 Examples of $\mathrm{LOH}$ and X-chromosome inactivation studies. Composite of LOH study results from several specimens. Each image (a-g) shows a normal, heterozygous result (left) and an abnormal, homozygous result (right) for (a) D7S2554, (b) D8S263, (c) D9S157, (d) D9S161, (e) D13S319, (f) TP53, and (g) X-chromosome inactivation. 
b
C

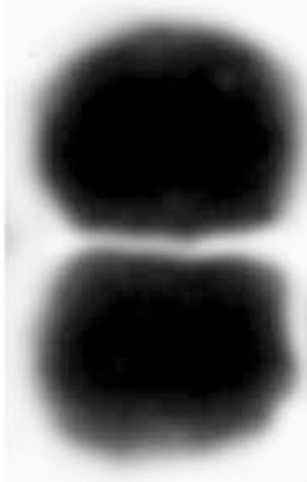

e

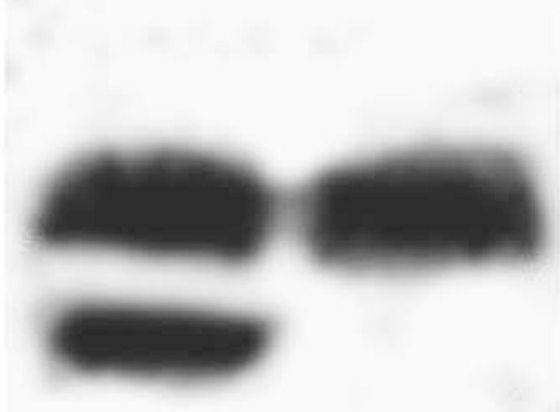

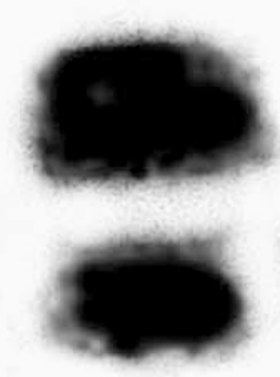

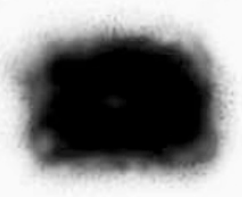

d
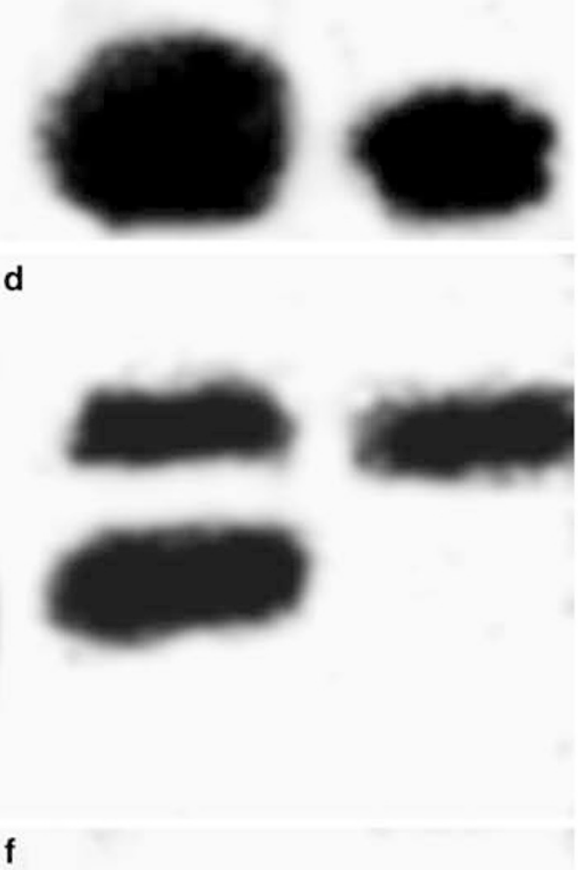

f
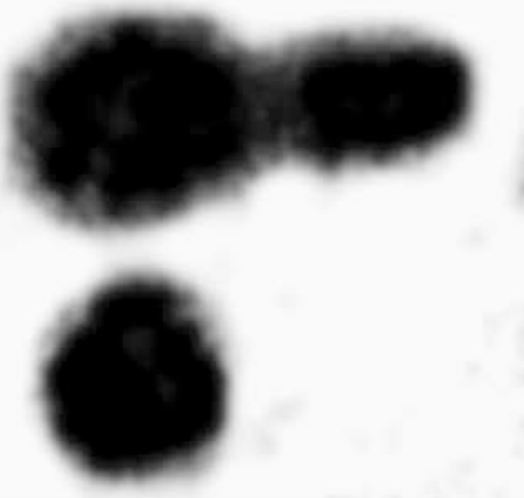

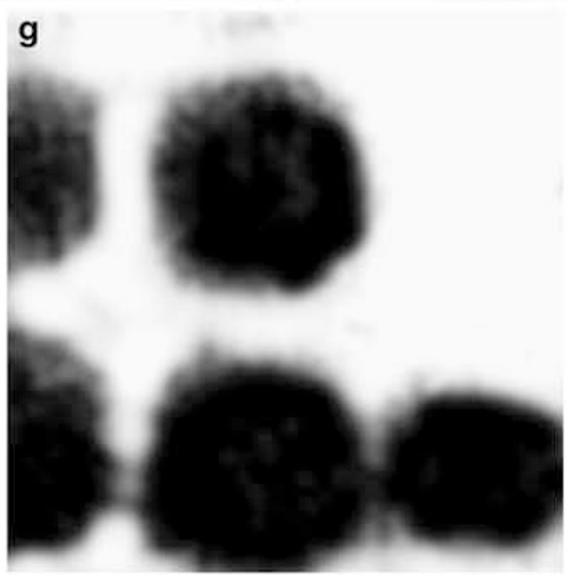


Table 2 Results of $\mathrm{LOH}$ and X chromosome inactivation studies

\begin{tabular}{|c|c|c|c|c|c|c|c|c|c|}
\hline Case & $D x$ & & D7S2554 & D8S263 & D9S157 & D9S161 & D13S319 & TP53 & $X \operatorname{chr}$ \\
\hline \multirow[t]{2}{*}{1} & CIMF & $\mathrm{C}$ & 0 & 0 & 0 & 0 & 0 & 0 & \\
\hline & & $\mathrm{T}$ & + & + & + & 0 & 0 & 0 & \\
\hline \multirow[t]{2}{*}{2} & CIMF & $\mathrm{C}$ & 0 & 0 & 0 & 0 & 0 & 0 & \\
\hline & & $\mathrm{T}$ & 0 & 0 & 0 & + & 0 & + & \\
\hline \multirow[t]{2}{*}{3} & CIMF & $\mathrm{C}$ & 0 & 0 & 0 & 0 & 0 & 0 & \\
\hline & & $\mathrm{T}$ & + & 0 & 0 & 0 & 0 & + & \\
\hline \multirow{2}{*}{4} & CIMF & C & 0 & 0 & 0 & 0 & 0 & 0 & $\mathrm{~N}$ \\
\hline & & $\mathrm{T}$ & 0 & 0 & 0 & 0 & 0 & 0 & $\mathrm{~N}$ \\
\hline \multirow[t]{2}{*}{5} & CIMF & C & 0 & $\mathrm{~N}$ & 0 & 0 & 0 & 0 & 0 \\
\hline & & $\mathrm{T}$ & 0 & $\mathrm{~N}$ & + & 0 & 0 & 0 & + \\
\hline \multirow[t]{2}{*}{6} & CIMF & C & 0 & 0 & 0 & 0 & 0 & 0 & 0 \\
\hline & & $\mathrm{T}$ & 0 & 0 & + & + & 0 & 0 & 0 \\
\hline \multirow[t]{2}{*}{7} & CML & $\mathrm{C}$ & 0 & 0 & $\mathrm{~N}$ & 0 & 0 & 0 & \\
\hline & & $\mathrm{T}$ & + & 0 & $\mathrm{~N}$ & + & 0 & + & \\
\hline \multirow[t]{2}{*}{8} & CML & $\mathrm{C}$ & 0 & 0 & 0 & 0 & 0 & 0 & \\
\hline & & $\mathrm{T}$ & 0 & 0 & 0 & 0 & 0 & + & \\
\hline \multirow[t]{2}{*}{9} & CML & $\mathrm{C}$ & 0 & 0 & 0 & 0 & $\mathrm{~N}$ & 0 & \\
\hline & & $\mathrm{T}$ & 0 & + & 0 & + & $\mathrm{N}$ & + & \\
\hline \multirow[t]{2}{*}{10} & CML & $\mathrm{C}$ & 0 & $\mathrm{~N}$ & 0 & $\mathrm{~N}$ & 0 & 0 & \\
\hline & & $\mathrm{T}$ & 0 & $\mathrm{~N}$ & 0 & $\mathrm{~N}$ & + & + & \\
\hline \multirow[t]{2}{*}{11} & CML & $\mathrm{C}$ & 0 & 0 & 0 & 0 & 0 & 0 & \\
\hline & & $\mathrm{T}$ & 0 & 0 & 0 & 0 & 0 & 0 & \\
\hline \multirow[t]{2}{*}{12} & CML & C & 0 & 0 & 0 & 0 & 0 & 0 & \\
\hline & & $\mathrm{T}$ & 0 & 0 & 0 & + & + & 0 & \\
\hline \multirow[t]{2}{*}{13} & AML & $\mathrm{C}$ & $\mathrm{N}$ & $\mathrm{N}$ & $\mathrm{N}$ & $\mathrm{N}$ & $\mathrm{N}$ & $\mathrm{N}$ & \\
\hline & & $\mathrm{T}$ & $\mathrm{N}$ & $\mathrm{N}$ & $\mathrm{N}$ & $\mathrm{N}$ & $\mathrm{N}$ & $\mathrm{N}$ & \\
\hline \multirow[t]{2}{*}{14} & AML & $\mathrm{C}$ & 0 & $\mathrm{~N}$ & 0 & 0 & $\mathrm{~N}$ & 0 & \\
\hline & & $\mathrm{T}$ & + & $\mathrm{N}$ & + & + & $\mathrm{N}$ & 0 & \\
\hline \multirow[t]{2}{*}{15} & AML & $\mathrm{C}$ & 0 & 0 & 0 & 0 & 0 & 0 & \\
\hline & & $\mathrm{T}$ & 0 & + & 0 & 0 & + & 0 & \\
\hline \multirow[t]{2}{*}{16} & AML & C & 0 & 0 & 0 & 0 & 0 & 0 & 0 \\
\hline & & $\mathrm{T}$ & + & 0 & + & 0 & 0 & 0 & + \\
\hline \multirow[t]{2}{*}{17} & ET & C & 0 & 0 & 0 & 0 & 0 & 0 & 0 \\
\hline & & $\mathrm{T}$ & 0 & 0 & 0 & + & 0 & 0 & 0 \\
\hline
\end{tabular}

$\mathrm{C}=$ control tissue; $\mathrm{T}=$ neoplastic splenic tissue; $0=$ normal result; $+=$ allelic loss; $\mathrm{N}=$ noninformative study; $\mathrm{AML}=$ acute myeloid leukemia; $\mathrm{CML}=$ chronic myelogenous leukemia; $\mathrm{CIMF}=$ chronic idiopathic myelofibrosis; $\mathrm{ET}=$ essential thrombocythemia; $\mathrm{X}$ chr $=\mathrm{X}$-chromosome inactivation analysis.

different, and mutually exclusive, sets of abnormalities found in the two locations.

\section{Discussion}

Our results show that LOH abnormalities are common in the neoplastic EMH found in spleens of chronic myeloproliferative disorders and AML.
We found LOH abnormalities common to myeloproliferative disorders in most of the studied spleens $(88 \%)$. One to three LOH abnormalities were seen in 5/6 chronic idiopathic myelofibrosis, 5/6 CML, 1/1 essential thromocythemia, and 3/3 AML. The fact that such a high percentage of cases showed abnormalities by LOH analysis suggests that this methodology might be used as an adjunct to routine histopathologic diagnosis of these types of disorders 
in the spleen when conventional cytogenetics are not available. Further, in many cases, multiple abnormalities were seen.

Evidence of nonrandom X chromosome inactivation was seen in 2/4 of informative cases analyzed, confirming the clonal nature of the process. However, in the other two cases, nonrandom X chromosome inactivation was seen. Several studies have shown that random $\mathrm{X}$ chromosome inactivation may be observed in up to $50 \%$ of invasive cancers. ${ }^{11}$ There are a number of possible explanations including (1) incomplete digestion of DNA samples prepared from formalin-fixed, paraffin-embedded tissues, (2) contamination by normal tissues, (3) the presence of X chromosome aneuploidy, (4) the coexistence of multiple tumor subclones of independent origins, (5) reactivation of inactive $\mathrm{X}$ chromosome-linked genes, and (6) variable methylation patterns at the $\mathrm{CpG}$ sites of the androgen receptor locus. Rarely, other mechanisms may attribute to the inactive status of $\mathrm{X}$ chromosome in female subjects. ${ }^{11}$

\section{LOH in Chronic Idiopathic Myelofibrosis}

(6 cases)

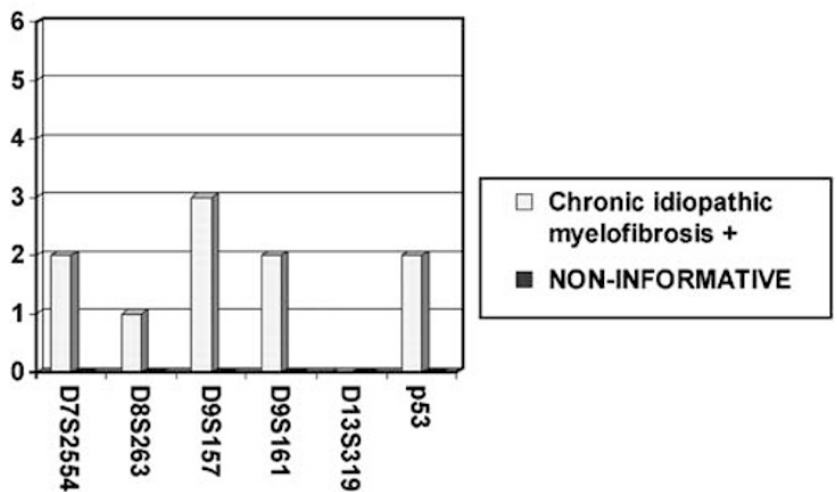

Figure $3 \mathrm{LOH}$ abnormalities in chronic idiopathic myelofibrosis. Summary of LOH findings in six chronic idiopathic myelofibrosis cases.
The results of the follow-up studies, comparing previously or concurrently obtained bone marrow biopsies to spleen samples, provided some interest-

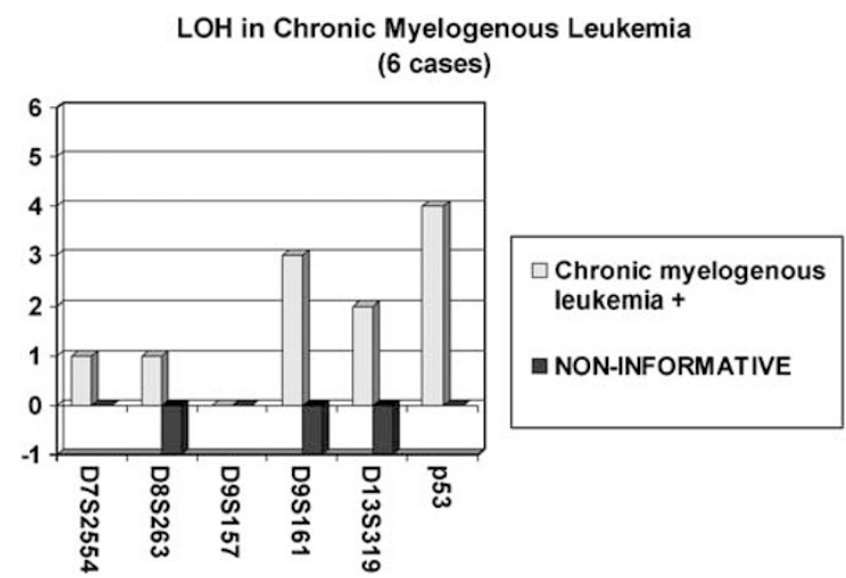

Figure 4 LOH abnormalities in CML. Summary of LOH findings in six CML cases.
$\mathrm{LOH}$ in Acute Myeloid Leukemia arising from Chronic Myeloproliferative Disorders (4 cases)

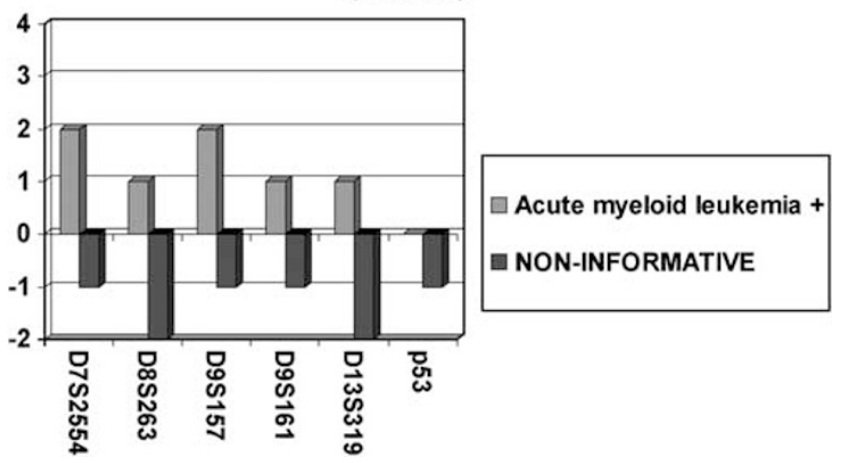

Figure $5 \mathrm{LOH}$ abnormalities in AML arising from previous chronic myeloproliferative disorders. Summary of LOH findings in four AML cases.

Table 3 Summary of findings in six cases comparing bone marrow and splenic LOH results

\begin{tabular}{|c|c|c|c|c|c|c|c|}
\hline & Site & D7S2254 & D8S263 & D9S157 & D9S161 & $D 13 S 319$ & p53 \\
\hline Case 2, CIMF & Spleen & 0 & 0 & 0 & + & 0 & + \\
\hline CIMF & Marrow & + & + & 0 & 0 & + & 0 \\
\hline Case 10, CML & Spleen & 0 & $\mathrm{~N}$ & 0 & $\mathrm{~N}$ & + & + \\
\hline CML & Marrow & 0 & $\mathrm{~N}$ & 0 & $\mathrm{~N}$ & 0 & + \\
\hline Case 11, CML & Spleen & 0 & 0 & 0 & 0 & 0 & 0 \\
\hline CML & Marrow & 0 & + & 0 & 0 & 0 & + \\
\hline Case 12, CML & Spleen & + & 0 & $\mathrm{~N}$ & + & 0 & + \\
\hline CML & Marrow & 0 & 0 & $\mathrm{~N}$ & + & 0 & 0 \\
\hline Case 14, AML & Spleen & + & $\mathrm{N}$ & + & + & $\mathrm{N}$ & 0 \\
\hline MPD, U & Marrow & + & $\mathrm{N}$ & 0 & + & $\mathrm{N}$ & + \\
\hline Case 15, AML & Spleen & 0 & + & 0 & 0 & + & 0 \\
\hline CMML & Marrow & 0 & 0 & 0 & 0 & + & 0 \\
\hline
\end{tabular}

'+' indicates allelic loss; red '+' indicates discordance in either marrow or spleen findings. '0' indicates normal finding. 'N' indicates a noninformative finding at an indivdual locus. AML = acute myeloid leukemia; CIMF = chronic idiopathic myelofibrosis; $\mathrm{CML}=\mathrm{chronic}$ myelogenous leukemia; $\mathrm{CMML}=$ chronic myelomonocytic leukemia; MPD, $\mathrm{U}=$ chronic myeloproliferative disease, unclassifiable. 
ing results. In four of the six cases, the spleen showed additional abnormal LOH loci compared to preceding marrows. This supports the observation that the spleen is a common site of clonal evolution and possibly blast transformation. ${ }^{15}$ In the single case of CML where the spleen showed no abnormal loci and the marrow did have $\mathrm{LOH}$ abnormalities, there are at least two possibilities that may account for this: (1) the spleens were a site of non-neoplastic hematopoiesis compared to abnormal marrows or (2) the spleens did not have any of the $\mathrm{LOH}$ abnormalities tested while the marrow had clonal progression compared to the spleen. It is difficult to distinguish which of these possibilities is more likely. The single case of chronic idiopathic myelofibrosis studied showed the most surprising results. The presence of multiple different and mutually exclusive $\mathrm{LOH}$ abnormalities between bone marrow and spleen may suggest that chronic idiopathic myelofibrosis is more clonally unstable with more heterogeneous lineage involvement than other chronic myeloproliferative disorder. ${ }^{6}$

In a recent study by Mesa et $a l^{15}$ using conventional cytogenetics, bone marrow and splenic karyotypes were compared in chronic idiopathic myelofibrosis. In this study, it was found that additional karyotypic abnormalities found in the spleen were associated with significantly worse postsplenectomy survival.

In conclusion, we demonstrate that clonal abnormalities are frequently present in spleens with neoplastic myeloid proliferations using $\mathrm{LOH}$ and Xchromosome inactivation analysis. The nature and evolution of neoplastic myeloid proliferations in the spleen, particularly in chronic myeloproliferative disorder, is a potentially rich area of future research. ${ }^{16}$ Although it is unlikely to be used as a primary diagnostic method, $\mathrm{LOH}$ studies may be of benefit in understanding nature of evolution of clonal cells and the detection of abnormal genetic findings in chronic myeloproliferative disorder and other hematopoietic disorders.

\section{Acknowledgement}

These results were presented in abstract form at the March 2005 annual USCAP meeting in San Antonio, Texas.

\section{References}

1 Freedman MH, Saunders EF. Hematopoiesis in the human spleen. Am J Hematol 1981;11:271-275.
2 O'Keane JC, Wolf BC, Neiman RS. The pathogenesis of splenic extramedullary hematopoiesis in metastatic carcinoma. Cancer 1989;63:1539-1543.

3 Wilkins BS, Green A, Wild AE, et al. Extramedullary haemopoiesis in fetal and adult human spleen: a quantitative immunohistological study. Histopathology 1994;24:241-247.

4 Neiman RS, Orazi A. Myeloproliferative disorders. In: Disorders of the Spleen, 2nd edn. W.B. Saunders: Philadelphia, 1999, pp 220-236.

5 Tripputi P, Cassani B, Alfano R, et al. Chromosome 7 monosomy and deletions in myeloproliferative diseases. Leuk Res 2001;25:735-739.

6 Reeder TL, Bailey RJ, Dewald GW, et al. Both B and T lymphocytes may be clonally involved in myelofibrosis with myeloid metaplasia. Blood 2003;101: 1981-1983.

7 Gribble SM, Reid AG, Roberts I, et al. Genomic imbalances in CML blast crisis: 8q24.12-q24.13 segment identified as a common region of overrepresentation. Genes Chromosomes Cancer 2003;37: 346-358.

8 Kralovics R, Buser AS, Teo SS, et al. Comparison of molecular markers in a cohort of patients with chronic myeloproliferative disorders. Blood 2003;102: 1869-1871.

9 Cheng L, Song SY, Pretlow TG, et al. Evidence of independent origin of multiple tumors from patients with prostate cancer. J Natl Cancer Inst 1998;90: 233-237.

$10 \mathrm{Gu}$ J, Roth LM, Younger C, et al. Molecular evidence for the independent origin of extra-ovarian papillary serous tumors of low malignant potential. J Natl Cancer Inst 2001;93:1147-1152.

11 Cheng L, Gu J, Eble JN, et al. Molecular genetic evidence for different clonal origin of components of human renal angiomyolipomas. Am J Surg Pathol 2001;25:1231-1236.

12 Brandli DW, Ulbright TM, Foster RS, et al. Stroma adjacent to metastatic mature teratoma after chemotherapy for testicular germ cell tumors is derived from the same progenitor cells as the teratoma. Cancer Res 2003;63:6063-6068.

13 Kernek KM, Ulbright TM, Zhang S, et al. Identical allelic losses in mature teratoma and other histologic components of malignant mixed germ cell tumors of the testis. Am J Pathol 2003;163:2477-2484.

14 McCarthy RP, Zhang S, Bostwick DG, et al. Molecular genetic evidence for different clonal origins of epithelial and stromal components of phyllodes tumor of the prostate. Am J Pathol 2004;165:1395-1400.

15 Mesa RA, Li CY, Schroeder G, et al. Clinical correlates of splenic histopathology and splenic karyotype in myelofibrosis with myeloid metaplasia. Blood 2001; 97:3665-3667.

16 O’Malley DP, Kim YS, Perkins S, et al. Morphologic and immunohistochemical evaluation of splenic hematopoietic proliferations in neoplastic and benign disorders. Mod Pathol (THIS ISSUE-article submitted to this journal simultaneously). 